Check for updates

Cite this: Mater. Chem. Front., 2021, 5, 3458

Received 18th January 2021 , Accepted 14th March 2021

DOI: 10.1039/d1qm00091h

rsc.li/frontiers-materials

\title{
Supramolecular aggregation properties of 4-(1-morpholino)-1,8-naphthalimide based fluorescent materials $\dagger$
}

\author{
June I. Lovitt, (D)*ab Tumpa Gorai, (D) a Emanuele Cappello, ${ }^{a}$ Jason M. Delente, (D) a \\ Sebastian T. Barwich, ${ }^{C}$ Matthias E. Möbius, (D) ${ }^{c}$ Thorfinnur Gunnlaugsson (D) *abd and \\ Chris S. Hawes (D)*e
}

\begin{abstract}
Here we report the synthesis of two morpholino-substituted naphthalimide ligands, $N$-(3-picolyl)-4-(1morpholino)-1,8-naphthalimide L1 and N-benzyl-4-(1-morpholino)-1,8-naphthalimide L2, and study their supramolecular properties in the crystalline, solution and gel phases. These ligands were designed through incorporation of the morpholino group to enhance their photophysical and $\mathrm{pH}$-responsive properties following recently reported $\mathrm{N}$-(3-picolyl) naphthalimide metallogels. L1 was found to form metallogels on reaction with either $\mathrm{Mn}^{2+}$ or $\mathrm{Co}^{2+}$. The gels were found to be thermally and chemically responsive to various stimuli including $\mathrm{pH}$. Conversely, L2 showed no reaction or coordination with transition metals, and did not gel under analogous conditions to $\mathbf{L} \mathbf{1}$. In the solution state, the fluorescence of both $\mathbf{L} \mathbf{1}$ and $\mathbf{L} \mathbf{2}$ exhibited $\mathrm{pH}$ responsiveness and counterion-influenced aggregation. The microparticle formation over the $\mathrm{pH}$ range was further investigated through Dynamic Light Scattering and Scanning Electron Microscopy. These two ligands illustrate how a modular ligand family can derive structure-function relationships and allow for systematic tuning, thus allowing for the future development of luminescent $\mathrm{pH}$ responsive soft materials.
\end{abstract}

\section{Introduction}

The development of stimuli-responsive materials using functional supramolecular constituents is an intriguing area within the materials science field. ${ }^{1 a-g}$ Weak noncovalent interactions can be fractured and reformed in response to several external chemical stimuli such as light, sonication, temperature, mechanical force and addition of other chemical components. ${ }^{2 a-c}$ Chemical changes to local environments yielding fluorometric and colorimetric responses have been widely incorporated into sensors for signalling in biological media, $\mathrm{pH}$ and ions. ${ }^{3 a-e}$

\footnotetext{
${ }^{a}$ School of Chemistry and Trinity Biomedical Sciences Institute, Trinity College Dublin, The University of Dublin, Dublin 2, Ireland. E-mail: jlovitt@tcd.ie, gunnlaut@tcd.ie

${ }^{b}$ AMBER (Advanced Materials and Bioengineering Research) Centre, Trinity College Dublin, The University of Dublin, Dublin 2, Ireland ${ }^{c}$ School of Physics, Trinity College Dublin, The University of Dublin, Dublin 2, Ireland

${ }^{d}$ Synthesis and Solid State Pharmaceutical Centre (SSPC), Ireland

${ }^{e}$ School of Chemical and Physical Sciences, Keele University, Keele ST5 5BG, UK. E-mail: c.s.hawes@keele.ac.uk

$\dagger$ Electronic supplementary information (ESI) available: Thermogravimetric analysis data, X-ray powder diffraction plots, UV-vis and NMR spectroscopy. CCDC 20482842048287. For ESI and crystallographic data in CIF or other electronic format see DOI: 10.1039/d1qm00091h
}

The ligand design can incorporate motifs which behave as fluorescent sensors for Lewis acids, including protons and/or metal ions. $^{4 a, b}$

The 1,8-naphthalimide fluorophore has been consistently utilised in supramolecular chemistry as a versatile building block to develop diverse libraries of organic ligands and metalorganic motifs. ${ }^{5 a-d}$ This framework is an attractive building block due to ease of functionalisation and excellent photophysical properties which result in a wide range of applications. ${ }^{6 a, b}$ In particular, 4-amino-1,8-naphthalimide derivatives are popular as fluorescent probes due to the delocalisation that can occur from the amino group into the naphthalimide causing a 'push-pull' based internal charge transfer (ICT) to occur in a fluorophorespacer-receptor design. ${ }^{7 a, b}$ The related 4-morpholino-1,8-naphthalimides are mainly used as fluorescent probes for biological systems, including in diverse applications in cell imaging, trace analyte detection and signalling in biological media but the coordination chemistry of these ligands remains relatively underexplored. ${ }^{8 a-d}$

The preparation of supramolecular gels and their subset, metallogels, using low-molecular-weight-gelators (LMWGs) has been successfully demonstrated in various applications such as drug delivery, catalysis and photonics, with commercial importance in a range of industries..$^{9 a-e}$ Stimuli responsive behaviour can be 
introduced into LMWGs containing metal binding groups (such as pyridine, bipyridine, triazole or carboxylate) or metal ions from tuning the underlaying coordination chemistry. ${ }^{10 a-e}$ A wealth of metallogels containing d-block metal ions have been reported including a nickel(II) metallogel formed from a bis(3-pyridylimine) ligand reported by Gloe et al., ${ }^{11}$ and a metallogel formed from a trimesic amide ligand induced by iron(III)/iron(II) was prepared by Huang et al. ${ }^{12}$ Another nickel(II) based metallogel formed from a triazole ligand by Mitra et al. has illustrated the dual function of reversible adsorption of toxic gases and sequestration of heavy metal ions, via gel to gel transformations due to the dynamic nature of $\mathrm{Ni}-\mathrm{N}_{\text {triazole }}$ interactions. ${ }^{9 b}$ An alternative design method is utilising the donor-acceptor properties of the ligands to form a thermally responsive silver(I) gel based on charge-transfer complex formation which has been reported by Bhattacharya et $a l^{13 a, b}$ We have previously reported responsive gels based on various scaffolds, including the 1,3,5-benzenetricarboxamide (BTA) motif, which itself is often functionalised to form supramolecular gelator ligands and can form luminescent metallogels through subsequent metalation with lanthanide ions. ${ }^{14 a-c, 15 a-c}$ In another study, we generated a series of luminescent lanthanide metallogels from both 2,6-bis(1,2,3-triazol4-yl)pyridine (BTP) and pyridine-2,6-dicarboxamide (DPA) chelators. ${ }^{16 a, b}$ More recently, we have reported a reversibly formed silver(I) metallogel with a 3-pyridyl substituted 1,2,3-triazol-4-ylpicolinamide (tzpa) ligand. ${ }^{17}$ However, despite a multitude of stimuli responsive materials there are relatively few examples in the literature of $\mathrm{pH}$ responsive metallogels incorporating a fluorescence sensor motif into the metallogels design.

We have recently reported a series of $N$-picolyl-1,8-naphthalimide derivatives and explored their coordination chemistry with d-block metal ions in the solid and solution states as well as exploited the structural and chemical properties of these ligands to generate a family of robust metallogels. ${ }^{18}$ The gels were found to be thermally and chemically reversible under various stimuli and similar materials could be generated by installing a piperidinyl substituent at the naphthalimide 4-position, giving intensely coloured gels. However, the effect of supramolecular aggregation on the photophysical properties of this system could not be measured.

Herein, we present a new study into the behaviour of these 3-picolylimide-substituted naphthalimide derivatives with the synthesis of two new fluorophores $N$-(3-picolyl)-4-(1-morpholino)-

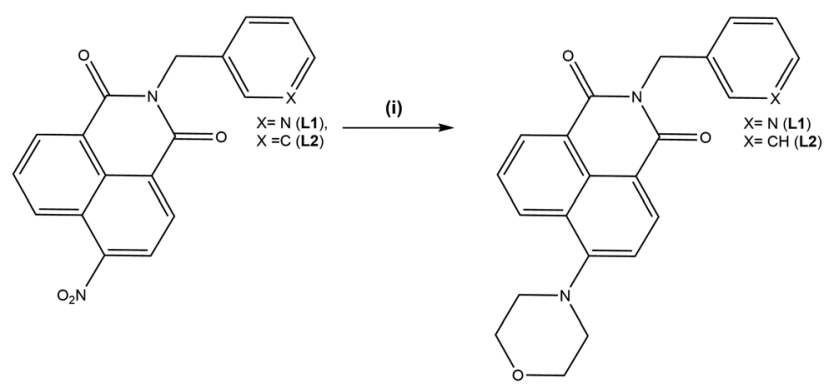

Scheme 1 Synthesis and structure of the ligands L1 and L2. Reagents and conditions: (i) morpholine, DMF, $140{ }^{\circ} \mathrm{C}$. 1,8-naphthalimide and $N$-(benzyl)-4-(1-morpholino)-1,8-naphthalimide, as shown in Scheme 1, and study their supramolecular properties in the crystalline, solution and gel phases. The tunability of this system is realised in both the solution and gelation phases, showing that this system has future potential in the development and application of luminescent $\mathrm{pH}$ responsive materials.

\section{Results and discussion}

\section{Synthesis and solid-state characterisation of L1-L2}

The ligands $N$-(3-picolyl)-4-(1-morpholino)-1,8-naphthalimide $\mathbf{L 1}$ and $N$-(benzyl)-4-(1-morpholino)-1,8-naphthalimide L2 were prepared based on modified literature procedures. ${ }^{18}$ By using morpholino substituted naphthalimides we envisaged analogous coordination chemistry to that previously observed for the $\mathrm{N}-(3-$ picolyl)-1,8-naphthalimide analogues, involving either monodentate coordination through the pyridine nitrogen atom as well as potential coordination through the morpholino nitrogen or oxygen atoms to softer Lewis acids such as silver(I). ${ }^{19}$ However, unlike the previous systems, the morpholino substituent allows new observations of the supramolecular aggregation effect on the photophysical properties of the system to be investigated by improving solubility while maintaining electron donor capabilities. The tunability of this system was examined through substituting the $\mathrm{N}$-position with benzylamine. This illustrated a structure-function relationship in the ligand design which can be used as a handle for developing the photophysical properties of this system.

Ligands $\mathbf{L 1}$ and $\mathbf{L} 2$ were prepared in two steps from the commercially available 4-nitro-1,8-naphthalic anhydride as shown in Scheme 1. Reaction of 3-picolyl amine with 4-nitro-1,8-naphthalic anhydride in acetic acid at reflux for 6 hours yielded L1a and L2a in $85 \%$ and $90 \%$ yield respectively. These could then be treated with the relevant amine giving the products $\mathbf{L 1}$ and $\mathbf{L} 2$ in yields $65 \%$ and $53 \%$. All precursors were characterised using conventional techniques, and the data were consistent with that previously reported. ${ }^{18}$ The characteristic morpholino resonances were present at 3.91 and $3.23 \mathrm{ppm}$ for $\mathbf{L 1}$ and 4.04 and $3.28 \mathrm{ppm}$ for $\mathbf{L 2}$ indicating conversion. The high-resolution mass spectrometry (HRMS) analysis of $\mathbf{L} 1$ and $\mathbf{L} 2$ showed peaks at $\mathrm{m} / z=374.1494$ and $m / z=373.1547$ respectively which corresponded to the protonated molecular ions $[\mathrm{M}+\mathrm{H}]^{+}$.

Single crystals of $\mathbf{L 1}$ suitable for X-ray diffraction analysis were prepared through dissolution in dilute aqueous $\mathrm{AcOH}(5 \% \mathrm{v} / \mathrm{v})$ and standing at room temperature for 7 days. Crystallographic data and refinement parameters are summarised in Table S1 (ESI $\dagger$ ). The X-ray diffraction analysis of colourless needle crystals provided a structural model in the chiral monoclinic space group $P 2_{1}$. The asymmetric unit contained one complete ligand molecule with four fully occupied water molecules per ligand molecule, as shown in Fig. 1. The morpholino group adopts a chair conformation with the nitrogen atom resisting full planarization with the naphthalimide, being located $0.40 \AA$ from the mean plane of its substituent carbon atoms. Nonetheless, in solution it is expected that this group may partially conjugate with the naphthalimide ring, lowering its basicity compared to free morpholine. The 3-pyridyl substituent 


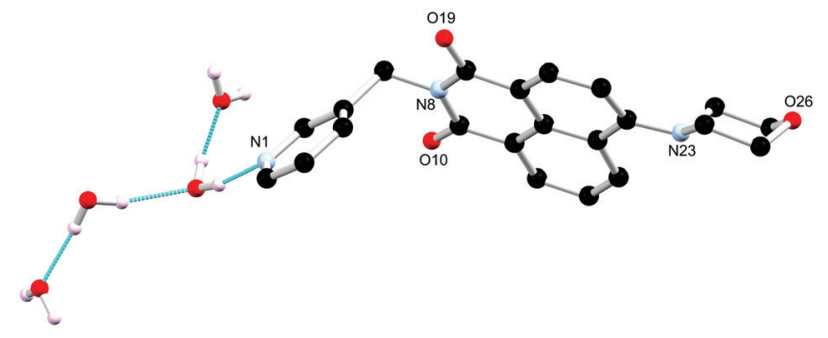

Fig. 1 Structure of $\mathbf{L} \mathbf{1}$ with heteroatom labelling scheme. Selected hydrogen atoms omitted for clarity.

attached to the imide nitrogen atom faces outwards, with an angle around the methylene group (N8-C7-C5) of $112.2(3)^{\circ}$. The orientation of the morpholino group results in a complementary hydrogen bonding array between four fully occupied water molecules in the asymmetric unit, as illustrated in Fig. 2.

The extended structure of $\mathbf{L} \mathbf{1}$ features offset symmetric faceto-face $\pi \cdots \pi$ stacking interactions between adjacent naphthalimide rings, the distance between the rings (C13 to C17) is $3.712 \AA$. There is also an extensive hydrogen bonding network with both ring motifs such as $\mathbf{R}_{6}^{6}(\mathbf{1 2})$ as well as chain motifs, $\mathbf{C}_{3}^{3}(\mathbf{1 9})$ and $\mathbf{C}_{2}^{2}(\mathbf{4})$, between the ligand units and the water molecules in each unit cell present. ${ }^{20}$ These intermolecular interactions link the naphthalimide oxygen to the water molecules (O19 to O32 is 2.851(4) $\AA$ ), and pyridyl nitrogen atom to the water molecules ( $\mathrm{N} 1$ to $\mathrm{O} 30$ is $2.759(4) \AA$ ) between the adjacent units. These interactions support the face-to-face $\pi \cdots \pi$ stacking interactions within sheets and head to tail $\pi \cdots \pi$ stacking interactions between adjacent sheets of the ligand. This is illustrated in Fig. 2 and Fig. S2 (ESI $\dagger$ ).

The acentric packing in this structure relates to the steric bulk of the morpholino group combined with the stabilising interactions of the lattice solvent molecules. Previously, with other substituents (such as nitro or halogen groups) we see alternating positions between two semi-equivalent naphthalimide 4-positions, which often also relates to crystallographic disorder. ${ }^{18,21}$ In the extended structure of L1, however, all the morpholino substituents stack on the same side of the naphthalimide. To limit steric clash between adjacent columns, the

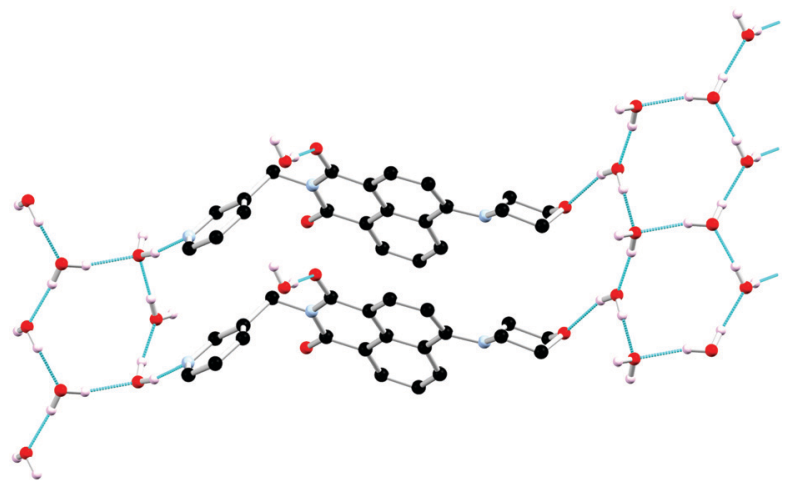

Fig. 2 Extended structure of L1 featuring hydrogen bonding and $\pi \cdots \pi$ stacking interactions between adjacent ligand moieties. Hydrogen atoms not involved in hydrogen bonding are omitted for clarity. morpholine substituents are unidirectional along $b$, prohibiting the expected glide symmetry and implying some level of longrange ordering in the columnar arrangement of this species. The acentric packing also influences the hydrogen bonding network which orients parallel to the naphthalimide stacks. While only a single crystalline phase could be observed visually, PXRD indicated the presence of several additional microcrystalline phases within the bulk sample isolated from the mother liquor. We were unable to fully ascertain the nature of the additional phase(s), though several of the Bragg reflections matched those expected from a small quantity of morpholinium acetate (ESI, $\uparrow$ Fig. S7 and S8).

In order to probe the coordination behaviour of L1, first row transition metals were screened such as cobalt(II) chloride in acetonitrile, which subsequently formed a metallogel, Co-L1. The chemical properties of the gel were investigated (vide infra), including the $\mathrm{pH}$ responsiveness. A small quantity of single crystals of L1-gel were generated from acid/base additions to the Co-L1 gel. Following the addition of $\mathrm{HCl}(0.1 \mathrm{M}, 100 \mu \mathrm{L})$ and subsequently of $\mathrm{NaOH}(0.1 \mathrm{M}, 100 \mu \mathrm{L})$ and brief sonication, the gel broke into a green solution which upon standing for 7 days formed yellow needle crystals. The X-ray diffraction analysis provided a structural model of L1-gel in the monoclinic $P 2_{1} / c$ space group. The asymmetric unit contained one complete ligand molecule and no solvent molecules. The substituents adopt a similar conformation to those described above; the morpholino group adopts a chair conformation with an equivalent deviation from planarity for the morpholine nitrogen atom of $0.40 \AA$. The $N$-substituted 3-pyridyl group faces outwards and exhibits an equivalent angle about the methylene group of $112.8(5)^{\circ}$ as illustrated in Fig. 3 a.

The extended structure of L1-gel features offset head-to-tail $\pi \cdots \pi$ stacking interactions between adjacent naphthalimide rings with centroid-centroid distance of $3.58 \AA$ and a perpendicular slip distance of $2.17 \AA$. Additionally, there are edge-to-face $\mathrm{C}-\mathrm{H} \cdots \mathrm{O}$ interactions in the $b$ direction between the naphthalimide oxygen atoms and the adjacent naphthalimide $\mathrm{C}-\mathrm{H}$ groups $(\mathrm{O} 10 \cdots \mathrm{C} 14$ is $3.320(6) \AA$, $\mathrm{C} 14-\mathrm{H} 14 \cdots \mathrm{O} 10$ angle is $\left.137.5(3)^{\circ}\right)$ which forms corrugated layers as illustrated in Fig. 3b. The structure of L1-gel is an anhydrate, with no water or other guest molecules present in the lattice. The role of solvation is apparent here as in the absence of the water molecules a very different arrangement is
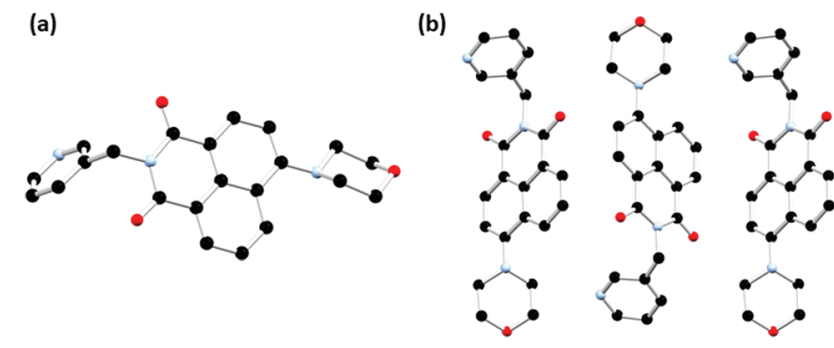

Fig. 3 (a) Structure of L1-gel from dissolution of the gel sample. Hydrogen atoms are omitted for clarity. (b) Extended structure of $\mathbf{L} \mathbf{1}$ featuring offset head-to-tail $\pi \cdots \pi$ stacking interactions between adjacent naphthalimide rings. Hydrogen atoms are omitted for clarity. 
adopted. A centrosymmetric packing mode is observed in this structure; although each column maintains a directional orientation of the morpholine group, adjacent columns along $b$ are inverted with respect to one another. This arrangement contrasts greatly from the $\mathbf{L 1}$ hydrate structure described above and indicates that the acentric inter-column ordering may be mediated by the lattice hydrogen bonding in the hydrate. These structural changes illustrate the influence solvation can have on the packing mode adopted in these species and may be consequential for the behaviour of the subsequent materials.

Single crystals suitable for X-ray diffraction analysis of L2a, the nitro precursor to $\mathbf{L} 2$, were prepared through dissolution in hot ethyl acetate and obtained after slow evaporation over 24 hours. The X-ray diffraction analysis of orange block crystals provided a structural model in the orthorhombic Pbca space group. There is one complete molecule of L2a in the asymmetric unit and no solvent or guest molecules present, as illustrated in Fig. 4. The extended structure of $\mathbf{L} 2 \mathbf{a}$ features offset face-to-face $\pi \cdots \pi$ stacking interactions between adjacent naphthalimide rings in which adjacent naphthalimide ring are twisted antiparallel to one another. The mean interplanar distance is 3.38 A with a slip distance of $3.13 \AA$. Additional $\mathrm{C}-\mathrm{H} \cdots \mathrm{O} / \mathrm{N}$ interactions provide further stabilisation to the overall architecture in the structure. The phase purity was determined through X-ray powder diffraction. The measured diffraction pattern of L2a matches well with the simulated powder diffraction pattern at $100 \mathrm{~K}$ of the crystal indicating that the crystallinity of the ligand was retained in the bulk structure and that this species crystallises as a single phase, as illustrated in Fig. S9 (ESI $\dagger$ ).

Single crystals suitable for X-ray diffraction analysis of $\mathbf{L 2}$ were prepared through dissolution in hot ethyl acetate and obtained after slow evaporation over 24 hours. The X-ray diffraction analysis of yellow block crystals provided a structural model in the monoclinic $P 2_{1} / c$ space group. There is one complete molecule of $\mathbf{L} \mathbf{2}$ in the asymmetric unit and no solvent or guest molecules present within the lattice as illustrated in Fig. 5. Similarly to the two phases of $\mathbf{L 1}$ the morpholino group again adopts a chair conformation, though the nitrogen atom is slightly more planarized, residing 0.35 A from the mean plane of its carbon substituents. The benzyl substituent at the $N$-position of the naphthalimide exhibits an angle about the methylene group (C4-C7-N8) of $113.86(15)^{\circ}$ which is comparable to that observed in the 3-pyridyl morpholino derivative $\mathbf{L 1}$.

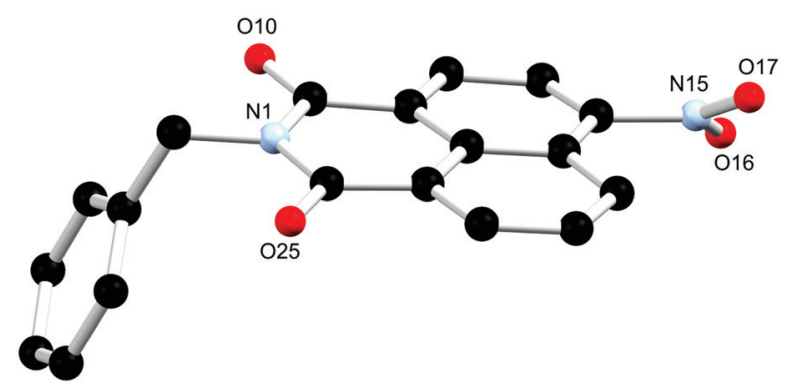

Fig. 4 Structure of L2a with heteroatom labelling scheme. All hydrogen atoms are omitted for clarity.

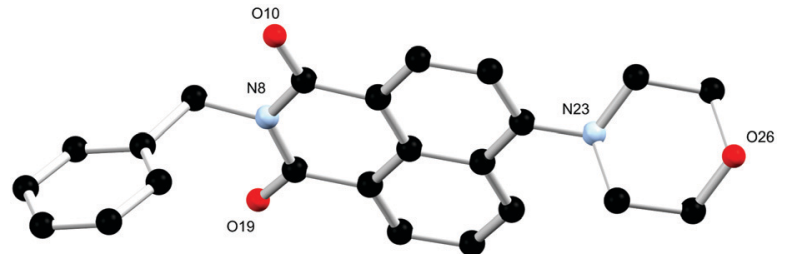

Fig. 5 Structure of L2 with heteroatom labelling scheme. All hydrogen atoms are omitted for clarity.

The chosen $\mathrm{N}$-substituent influences the structure directionality. In the $\mathbf{L} 1$ structures, the pyridyl nitrogen atom can be further implicated in $\mathrm{C}-\mathrm{H} \cdots \mathrm{N}$ interactions as well as interactions with the lattice water molecules in the case of the hydrated ligand structure. Whereas the benzyl substituted ligands, $\mathbf{L} \mathbf{2}$ a and $\mathbf{L 2}$, favour more $\mathrm{C}-\mathrm{H} \cdots \mathrm{O}$ interactions as well as $\pi \cdots \pi$ interactions. This is particularly evident when comparing the calculated Hirshfeld surfaces and resultant fingerprint plots of each molecule (ESI, $\dagger$ Fig. S5 and S6). The extended structure of $\mathbf{L} 2$ features offset head-to-tail $\pi \cdots \pi$ stacking interactions between adjacent naphthalimide rings with a mean interplanar distance of $3.23 \AA$ and a slip distance of $4.66 \AA$ between the two naphthyl centroids. The large slip distance between the two naphthyl centroids indicates that direct interaction is only achieved at the periphery of the molecule. There are few significant $\mathrm{C}-\mathrm{H} \cdots \pi$ interactions that occur between adjacent ligand moieties. In addition to the $\pi \cdots \pi$ stacking interactions another $\mathrm{C}-\mathrm{H} \cdots \mathrm{O}$ interaction occurs between the naphthalimide oxygen and the adjacent benzyl hydrogen atom

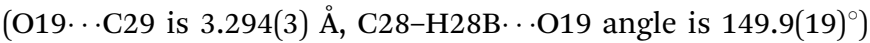
which supports this offset conformation adopted by the ligand. This is illustrated in Fig. 6 and Fig. S4 (ESI $\dagger$ ). The X-ray powder diffraction pattern of $\mathbf{L} 2$ matches well with the simulated powder diffraction pattern at $100 \mathrm{~K}$ of the crystal indicating the presence of a single phase and that the crystallinity of the ligand was retained on drying, as illustrated in Fig. S10 (ESI $\dagger$ ).

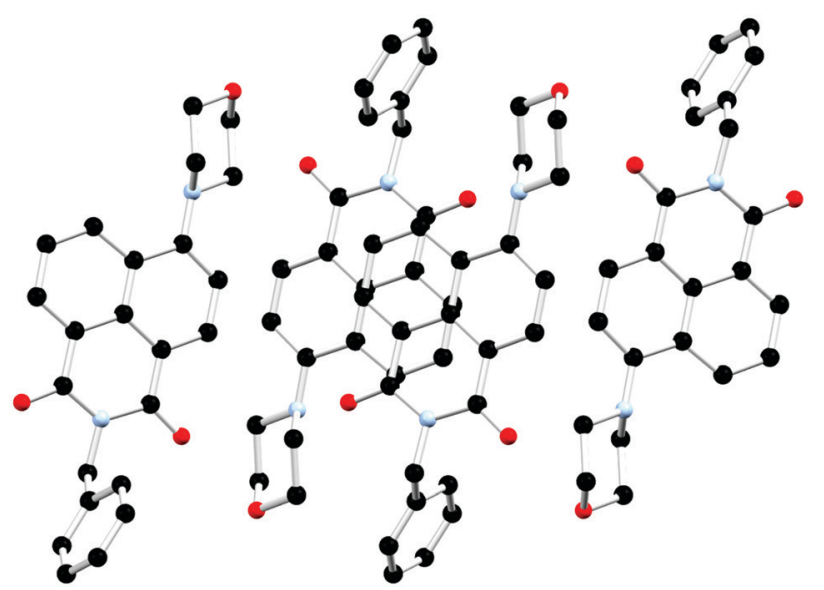

Fig. 6 Extended structure of L2 featuring offset head-to-tail $\pi \cdots \pi$ stacking interactions between adjacent naphthalimide rings. Hydrogen atoms are omitted for clarity. 
The thermal stabilities of both $\mathbf{L 1}$ and $\mathbf{L} 2$ were probed through thermogravimetric analysis. Both ligands had moderate melting points ( $\mathrm{ca} .170{ }^{\circ} \mathrm{C}$ ) and maintained stable mass in TGA until above this temperature. A rapid single step decomposition of $\mathbf{L 1}$ above $280{ }^{\circ} \mathrm{C}$ was then observed, while a two-step decomposition was observed for $\mathbf{L} 2$ above $200{ }^{\circ} \mathrm{C}$. This further corroborates that both ligands have good thermal stabilities (Fig. S12 and S13, ESI $\dagger$ ).

\section{Solution studies of L1-L2}

A UV-visible absorption study of $\mathbf{L 1}$ and $\mathbf{L} 2$ was initially carried out in acetonitrile following solid state characterisation of these ligands. As illustrated in (Fig. S14, ESI $\dagger$ ), $\mathbf{L 1}$ and $\mathbf{L} 2$ shows several absorbance bands in the UV region with $\lambda_{\max } / \mathrm{nm}\left(\varepsilon_{\max } \times 10^{3} / \mathrm{L} \mathrm{mol}^{-1} \mathrm{~cm}^{-1}\right)$ : $255 \mathrm{~nm}(16.6 \pm 0.2), 400 \mathrm{~nm}(11.1 \pm 0.1)$ for $\mathbf{L 1}$, and $400 \mathrm{~nm}$ $(4.8 \pm 0.08)$ for $\mathbf{L} 2$. We initially attempted to determine the coordination chemistry of $\mathbf{L} \mathbf{1}$ and $\mathbf{L} 2$ in solution but addition of manganese(II) and cobalt(II) chloride in acetonitrile to these solutions led only to minor variations in the absolute absorbance intensity corresponding to build up of unreacted metal salt, with no significant changes to indicate that coordination was occurring at these concentrations.

As previously mentioned, 4-amino-1,8-naphthalimide derivatives are known to be strongly coloured and fluorescent due to the ICT. There is a large change in dipole between the ground and excited states with an associated reorganization of the solvent sphere, and therefore the Stokes shift is solvent polarity dependent. Hence, the absorption and emission spectra of $\mathbf{L 1}$ and $\mathbf{L} 2$ were recorded in different solvents with varying polarity including $\mathrm{CH}_{3} \mathrm{CN}$, DMSO, THF, $\mathrm{CH}_{3} \mathrm{OH}, \mathrm{CH}_{2} \mathrm{Cl}_{2}$, toluene and THF. The UV-vis absorption spectra of $\mathbf{L 1}$ and $\mathbf{L} 2$ in both protic and aprotic solvents showed a high-energy transition at $250 \mathrm{~nm}$ assigned to the $\pi-\pi^{*}$ transition and a low energy band at $400 \mathrm{~nm}$ assigned to the ICT transition. The fluorescence emission spectra of $\mathbf{L 1}$ exhibited modest solvatochromism; a red shift in the emission maxima is observed upon increasing the solvent polarizability. In addition to this, there is a large difference in fluorescence intensity as the solvent polarity increases, in solvents such as toluene and DCM there is a high fluorescence intensity, but the intensity decreases significantly when the study was repeated with
$\mathrm{CH}_{3} \mathrm{OH}$ and DMSO. For example, in toluene $(\varepsilon=2.4), \mathbf{L 1}$ exhibited blue emission at $508 \mathrm{~nm}$, while in $\mathrm{CH}_{3} \mathrm{CN}(\varepsilon=37.5)$, a yellow-green emission at $532 \mathrm{~nm}$ was observed. A similar solvatochromatic effect is observed for $\mathbf{L} 2$; in dichloromethane $(\varepsilon=8.9)$, $\mathbf{L} 2$ exhibited blue emission at $511 \mathrm{~nm}$, while in $\mathrm{CH}_{3} \mathrm{CN}(\varepsilon=37.5)$, a yellow-green emission at $530 \mathrm{~nm}$ was observed. The Lippert-Mataga equation was used to examine the influence of solvent on the emission spectra of $\mathbf{L 1}$ and $\mathbf{L 2} .^{22}$ This is visualised in the Lippert-Mataga plots, see Fig. S15 and S16 (ESI $\dagger$ ). We also observed that the Stokes shift increased significantly from $5900 \mathrm{~cm}^{-1}$ to $6700 \mathrm{~cm}^{-1}$ and $5700 \mathrm{~cm}^{-1}$ to $6300 \mathrm{~cm}^{-1}$ across the solvent polarity range for $\mathbf{L 1}$ and $\mathbf{L} 2$ respectively, in addition to the expected spectral broadening, consistent with the higher energy cost of solvent sphere reorganisation on increasing solvent polarity as illustrated in Tables S2 and S3 (ESI $\dagger$ ) and (Fig. 7 and Fig. S17, ESI $\dagger$ ).

To investigate potential aggregation-induced emission (AIE) behaviour of $\mathbf{L 1}$ and $\mathbf{L 2}$, the UV-vis absorption spectra and fluorescence emission spectra were measured of $\mathrm{CH}_{3} \mathrm{CN} / \mathrm{H}_{2} \mathrm{O}$ mixtures, with the expectation that increased water fraction would induce aggregation. As the percentage of $\mathrm{H}_{2} \mathrm{O}$ increased, however, no enhancement of fluorescence was observed. Instead, this led to a reduction in the observed emission intensity (ESI, $\dagger$ Fig. S18-S20), implying that aggregation is likely not a mechanism for emission enhancement in this system, which instead is most emissive as the free molecule in solution. A concentration dependent fluorescence study of $\mathbf{L 1}$ and $\mathbf{L 2}$ over the range $1 \times 10^{-4} \mathrm{M}$ to $1 \times 10^{-6} \mathrm{M}$ was also carried out in both $\mathrm{H}_{2} \mathrm{O}$ and $\mathrm{CH}_{3} \mathrm{CN}$; the normalised spectra remained essentially invariant over this range and no significant change to band shape was observed, further supporting that this system is not prone to AIE behaviour (ESI, † Fig. S21 and S22).

\section{pH solution studies of L1-L2}

Following the study of the fundamental photophysical properties of $\mathbf{L 1}$ and $\mathbf{L} 2$ we next investigated the changes in the photophysical properties of the molecules in aqueous solution as a function of $\mathrm{pH}$, by carrying out $\mathrm{pH}$ titrations from either acidic media to alkaline, or from alkaline to acidic media. The photophysical properties of $\mathbf{L 1}$ and $\mathbf{L} 2$ were first investigated as a function of $\mathrm{pH}$ in water, in the presence of $100 \mathrm{mM} \mathrm{NaCl}_{(\mathrm{aq})}$ to
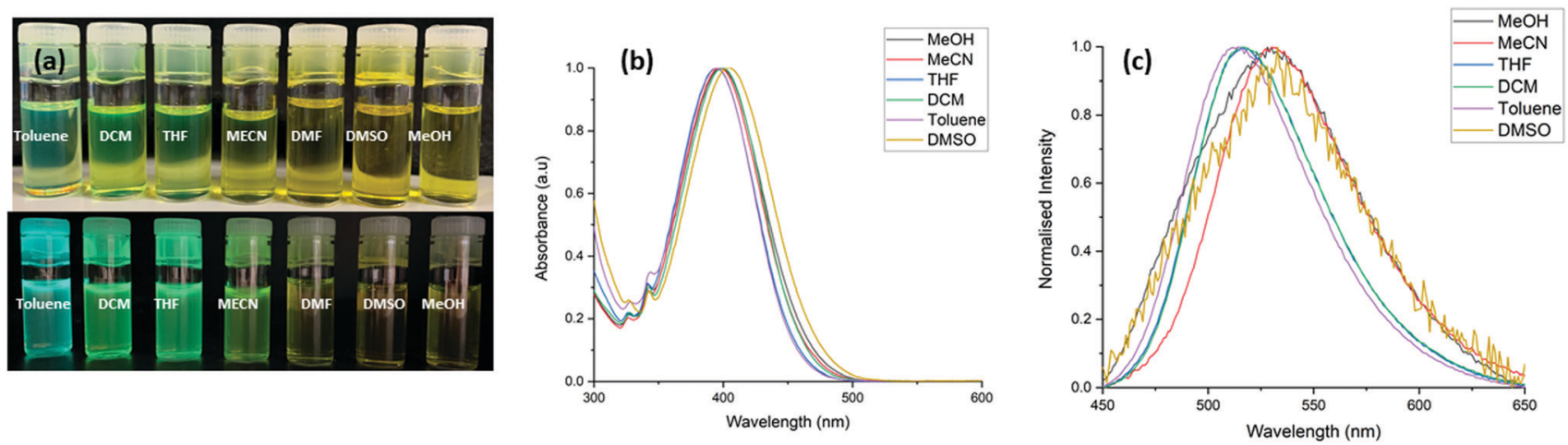

Fig. 7 (a) Corresponding photograph taken in room light and under UV light, (b) UV absorption spectra of L1 in solvents of varying polarity (c) normalised fluorescence spectra of $\mathbf{L} \mathbf{1}$ in solvents of varying polarity. 
maintain constant ionic strength. Initially at $\mathrm{pH} 2, \mathbf{L 1}$ is protonated and upon sequential additions of $\mathrm{NaOH}_{(\mathrm{aq})}$ deprotonation occurs. As can be seen in Fig. 8 there are significant absorbance changes observed both in the high energy transitions as well as in the ICT band from $380 \mathrm{~nm}$ to $450 \mathrm{~nm}$. As the $\mathrm{pH}$ increases from $\mathrm{pH} 2$ to $\mathrm{pH} 12$, particularly at $\mathrm{pH} 4.5-5$, there is a sharp decrease observed in UV absorbance with no corresponding new absorbance bands, suggesting the removal of chromophores from solution. A sharp increase in fluorescence emission accompanies the change in protonation state. As the pyridyl group is electronically isolated from the naphthalimide fluorophore, this change in photophysical behaviour could relate to aggregation once the cation-cation repulsion is removed and the solubility decreases. The increase in fluorescence emission could also relate to an aggregation process, either through the accessibility of new energy transfer modes, or the loss of a non-radiative decay pathway relating to the change in protonation state. Repeating this titration in reverse, starting in alkaline conditions at $\mathrm{pH} 12, \mathbf{L 1}$ is deprotonated and following sequential additions of $\mathrm{HCl}_{(\mathrm{aq})}$ protonation occurs, as shown in Fig. S24 and S25 (ESI $\dagger$ ). A hysteresis is also evident in the absorbance response of $\mathbf{L 1}$ to $\mathrm{pH}$, as illustrated in Fig. S26 (ESI $\dagger$ ), as the full intensity of the absorbance band is not recovered until pH 2.5 in the reverse titration. This observation is also consistent with a phase change for $\mathbf{L 1}$ between the protonated and deprotonated forms, rather than a fully solution phase acid-base equilibrium. The effect of counterions on the system was also investigated, and the titrations were repeated with a $\mathrm{HNO}_{3(\mathrm{aq})}$ spike (Fig. S27-S30, ESI $\dagger$ ) as well as an initial $\mathrm{CH}_{3} \mathrm{COOH}_{(\mathrm{aq})}$ spike (Fig. S31-S34, ESI $\dagger$ ) and hysteresis in the forward and reverse titrations was consistently observed. We also noted a difference in the onset pHs as a function of counterion, further consistent with an aggregation/ precipitation process rather than simple protonation equilibria. The counterion titrations were repeated in pure $\mathrm{H}_{2} \mathrm{O}$ media and the same effect was observed as previously described (Fig. S35-S38 for $\mathrm{HCl}_{(\mathrm{aq})}$, Fig. S39-S42 for $\mathrm{HNO}_{3(\mathrm{aq})}$ and Fig. S43-S46 for
$\left.\mathrm{CH}_{3} \mathrm{COOH}_{(\mathrm{aq})}, \mathrm{ESI} \dagger\right)$. The changes occurring in the ICT band could also indicate that some aggregation or slight dilution effects are being observed. Although photoinduced electron transfer (PET)type behaviour might be expected from this class of fluorophore, both the direction of emission enhancement (i.e., higher intensity at higher $\mathrm{pH}$ ) and the electronic isolation of the pyridyl nitrogen atom from the fluorophore would seem to disfavour such a process.

To further investigate the effect of the pyridyl group on the $\mathrm{pH}$ responsiveness of this motif, this study was repeated with the analogous benzyl derivative, L2, where one of the two possible protonation sites is removed. Initially in acidic conditions with $\mathrm{HCl}_{(\mathrm{aq})}$ spike at $\mathrm{pH} 2, \mathbf{L 2}$ has an absorbance $\lambda_{\max }$ at $400 \mathrm{~nm}$ and upon sequential additions of $\mathrm{NaOH}_{(\mathrm{aq})}$, there is a gradual decrease in absorbance until $\mathrm{pH}$ 5.5. In contrast to L1, above this $\mathrm{pH}$ into the alkaline region there is the formation of a new ICT band with $\lambda_{\max }$ at $455 \mathrm{~nm}$ which blue-shifts and gradually increases in intensity with sequential additions until pH 12 (Fig. S47, ESI $\dagger$ ). This effect is reversible; repeating the titration initially in alkaline conditions at $\mathrm{pH} \mathrm{12,} \mathbf{2} 2$ has a $\lambda_{\max }$ at $455 \mathrm{~nm}$ which gradually decreases in intensity until $\mathrm{pH} 6$ and below this $\mathrm{pH}$ into the acidic region there is growth of the original ICT band with $\lambda_{\max }$ at $400 \mathrm{~nm}$. The fluorescence intensity increases with excitation at $450 \mathrm{~nm}$ during the formation of this new band as the $\mathrm{pH}$ is increased (Fig. S48, ESI $\dagger$ ).

To investigate the effect of counterions, these titrations were repeated with a $\mathrm{HNO}_{3(\mathrm{aq})}$ spike (Fig. S49 and S50, ESI $\dagger$ ) as well as an initial $\mathrm{CH}_{3} \mathrm{COOH}_{(\mathrm{aq})}$ spike (Fig. S51 and S52, ESI $\dagger$ ) and the same phenomenon was observed. However, with acetic acid the fluorescence intensity was invariant in the same $\mathrm{pH}$ range. Finally, the $\mathbf{L} 2$ counterion titrations were repeated in $\mathrm{H}_{2} \mathrm{O}$ medium and the same effect was observed as described above (Fig. S53, S54 for $\mathrm{HCl}_{(\mathrm{aq})}$, Fig. S55, S56 for $\mathrm{HNO}_{3(\mathrm{aq})}$, Fig. 9 and Fig. $\mathrm{S} 57$ for $\mathrm{CH}_{3} \mathrm{COOH}_{(\mathrm{aq})}$, ESI $\left.\dagger\right)$. The counterion effect is summarised in Fig. S58 (ESI $\dagger$ ). There is variation in the isosbestic point in the titrations that is also indicative of aggregation. From the observations above it does not appear that $\mathbf{L 1}$ and $\mathbf{L} 2$ are
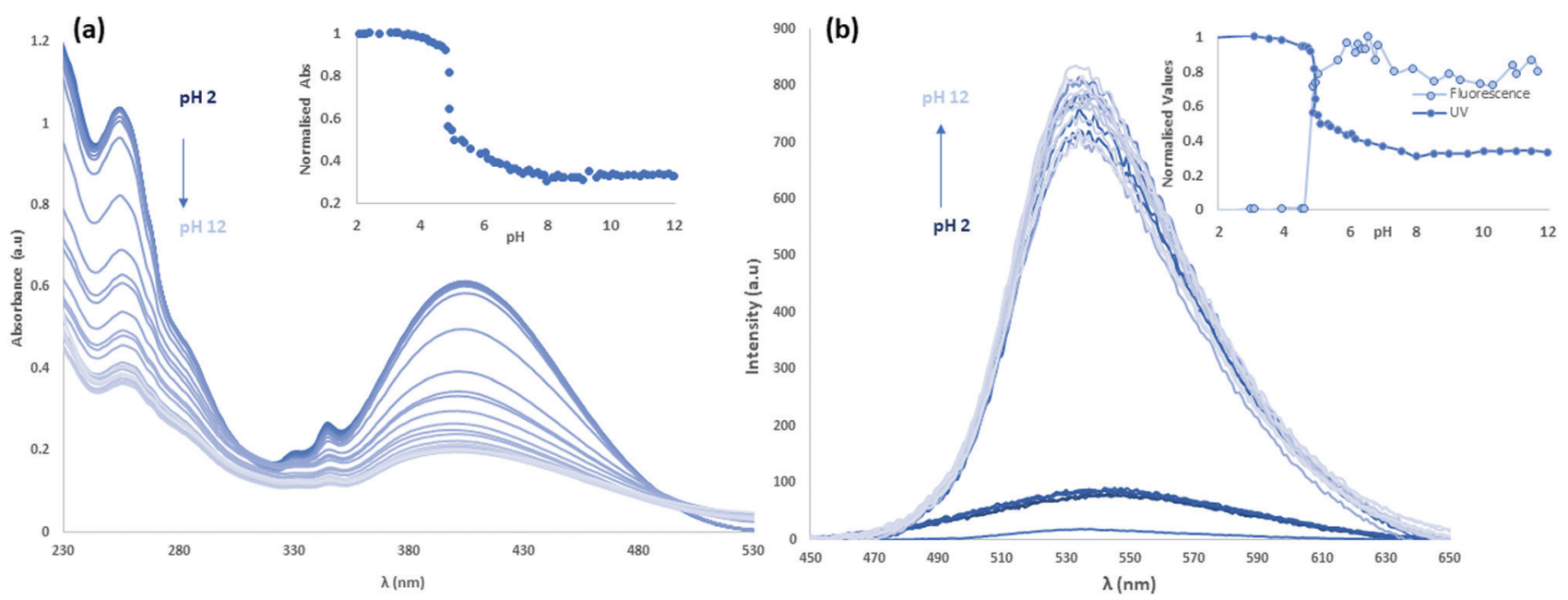

Fig. 8 (a) $\mathrm{UV}$-vis pH titration of $\mathbf{L} 1$ with $\mathrm{NaOH}_{(\text {(a) }}$ at $0.1 \mathrm{pH}$ unit intervals and an initial $\mathrm{HCl}_{(\text {(aq) }}$ acid spike in 100 mM NaCl$($ aq) medium. (inset) $\mathrm{Normalised}$ absorbance $\left(\lambda_{\max }=400 \mathrm{~nm}\right)$ of the titration. (b) Fluorescence $\mathrm{pH}$ titration of $\mathbf{L 1}$ with $\mathrm{NaOH}_{(\mathrm{aq})}$ at $0.1 \mathrm{pH}$ unit intervals and an initial $\mathrm{HCl}($ aq) acid spike in $100 \mathrm{mM} \mathrm{NaCl}$ (aq) medium. (inset) Normalised absorbance $\left(\lambda_{\max }=400 \mathrm{~nm}\right)$ and fluorescence of the titration $\left(\lambda_{\mathrm{ex}}=400 \mathrm{~nm}, \lambda_{\max }=550 \mathrm{~nm}\right)$. 
(a)

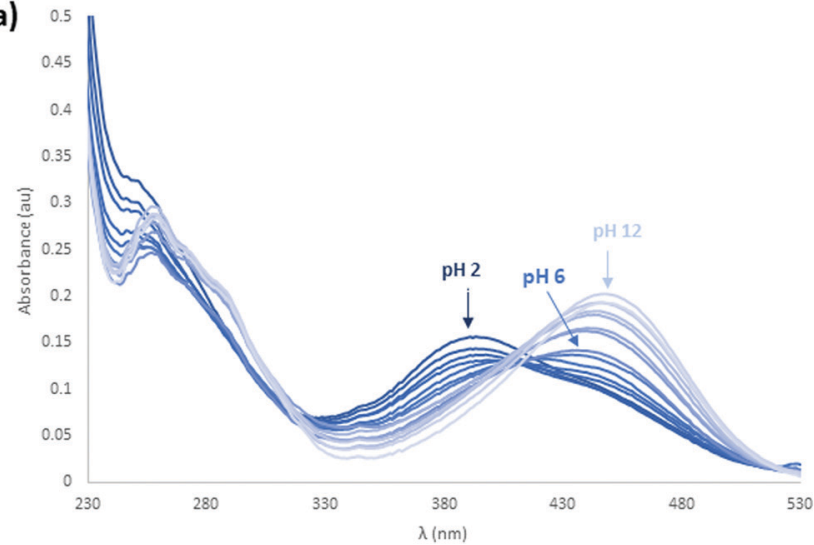

(b)

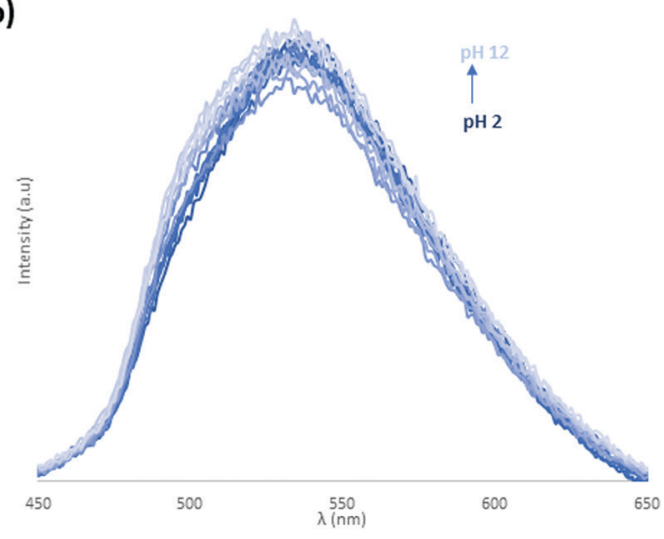

Fig. 9 (a) Representative UV-vis pH titration of $\mathbf{L} 2$ with additions of $\mathrm{NaOH}_{(a q)}$ at $0.1 \mathrm{pH}$ unit intervals and an initial $\mathrm{CH}_{3} \mathrm{COOH}_{(\mathrm{aq})}$ acid spike. (b) Representative fluorescence $\mathrm{pH}$ titration ( $\lambda_{\text {ex }}=400 \mathrm{~nm}$ ) with additions of $\mathrm{NaOH}_{(\mathrm{aq})}$ and an initial $\mathrm{CH}_{3} \mathrm{COOH}_{\text {(aq) }}$ acid spike in $\mathrm{H}_{2} \mathrm{O}$ medium.

undergoing a simple protonation and deprotonation process while remaining fully dissolved as there is both a change in the total absorbance with $\mathrm{pH}$ and a hysteresis with $\mathrm{pH}$, both of which are anion-dependent. The degree at which this occurs changes between $\mathbf{L} \mathbf{1}$ and $\mathbf{L} 2$, which suggests it is related to the pyridine functionality and not isolated to the morpholine group which is strongly coupled to the emission properties of the naphthalimide fluorophore. However, as no solids were observed to form in the cuvette and the total absorbance at higher wavelengths was not significantly affected by background scattering from the sample this suggests that the aggregates remain well dispersed, but also potentially larger than $1 \mu \mathrm{m}$. Therefore, this hypothesis was pursued by using Dynamic Light Scattering (DLS) and Scanning Electron Microscopy (SEM).

To examine the formation of aggregates over the $\mathrm{pH}$ range, samples of $\mathbf{L} \mathbf{1}$ and $\mathbf{L} \mathbf{2}$ were prepared for DLS measurements and SEM at $\mathrm{pH} 4,6$ and 8 with $\mathrm{HCl}_{(\mathrm{aq})}, \mathrm{HNO}_{3(\mathrm{aq})}$ and $\mathrm{HOAc}_{(\mathrm{aq})}$ initial acid spikes. The formation of micrometer-scale aggregates in solution was indicated as scattering occurred during the DLS measurements for both $\mathbf{L 1}$ and L2. However, in the DLS measurements the apparent polydispersity index for all samples is high $(>0.4)$ and therefore it is not possible to ascertain accurate size information or draw meaningful conclusions on trends of the particle size between samples. Following this, SEM was carried out, for the solutions at $\mathrm{pH} 4, \mathrm{pH} 6$ and $\mathrm{pH} 8$ with $\mathrm{HCl}_{(\mathrm{aq})}, \mathrm{HNO}_{3(\mathrm{aq})}$ and $\mathrm{HOAc}_{(\mathrm{aq})}$ spikes. The samples were deposited onto silicon wafers, evaporated under vacuum and subsequent imaging of the dried samples showed the presence of aggregates. In the dried $\mathbf{L} \mathbf{1}$ and $\mathbf{L} 2$ samples initially spiked with $\mathrm{HCl}_{(\mathrm{aq})}$ and $\mathrm{HNO}_{3(\mathrm{aq})}$ at $\mathrm{pH} 4$ there is the formation of branched aggregates with some ordered morphology and as the $\mathrm{pH}$ increases to $\mathrm{pH} 6$ there is the formation of a very high density of aggregates which lose their structured morphology. Upon a further increase to $\mathrm{pH} 8$ there is the formation of micrometer-scale aggregates which is consistent with the DLS measurements as illustrated in Fig. 10 and Fig. S59 (ESI $\dagger$ ). In contrast to this, the dried $\mathrm{CH}_{3} \mathrm{COOH}_{(\mathrm{aq})}$ samples for $\mathbf{L} 1$ and $\mathbf{L} 2$ have a very low number of aggregates at $\mathrm{pH} 4$ but more aggregation occurs at $\mathrm{pH} 6$ and then the presence of micrometre-sized aggregates is observed at $\mathrm{pH} 8$. The morphology of the dried $\mathrm{CH}_{3} \mathrm{COOH}_{(\mathrm{aq})}$ samples also differs from $\mathrm{HNO}_{3}$ and $\mathrm{HCl}$ samples as the $\mathrm{CH}_{3} \mathrm{COOH}_{(\mathrm{aq})}$ samples have a crystalline morphology at pH 4 and $\mathrm{pH} 6$ as illustrated in Fig. 10 and Fig. S59, S60 (ESI $\dagger$ ). This further illustrates the role that the counterions play in the deprotonation and protonation events, correlating to the spectroscopic findings.

\section{Metallogel formation}

From the observations above, it is evident that $\mathbf{L 1}$ and $\mathbf{L} 2$ are likely exhibiting various solution-phase aggregation processes which are sensitive to the protonation state. In order to further probe the supramolecular assembly characteristics of these systems we examined the interaction of $\mathbf{L} \mathbf{1}$ and $\mathbf{L} \mathbf{2}$ with other Lewis acids, using first row transition metal ions as our test case based on successful gelation experiments with similar compounds. By incorporating a fluorescent sensor motif into the metallogel design a $\mathrm{pH}$ responsive material could be generated, with potential applications in luminescent sensing.

In order to probe the coordination behaviour of $\mathbf{L 1}$ and $\mathbf{L 2}$, a range of solvent systems (toluene, hexane, chloroform, dichloromethane, ethyl acetate, acetonitrile, acetone, THF, methanol and mixtures of these solvents), various first-row transition metal ions with different counterions as well as a variety of standard crystallisation techniques were screened but only amorphous or microcrystalline powders were generated.

The reaction of $\mathbf{L 1}$ with manganese(II) (1), cobalt(II) (2) and nickel(II) (3) as their chloride salts in acetonitrile at $10 \mathrm{mM}$ concentration (ca. $1.0 \mathrm{wt} \%$ ) gave viscous, homogeneous solutions which set into clear and homogeneous metallogels in sealed sample tubes over a 48 hour period. The green cobalt and pale-yellow manganese gels resist inversion in wide-bore sample tubes indefinitely as illustrated in Fig. 11. In comparison, the nickel equivalent forms a considerably less robust gel and is unstable to inversion over a matter of seconds. This is consistent with what has been previously observed for this system. In contrast, reaction of $\mathbf{L} \mathbf{2}$ under analogous conditions with the same metal salts yielded amorphous or microcrystalline precipitate, indicating the requirement for the strongly coordinating 3-picolyl group in the metallogel formation. The reaction of $\mathbf{L} 2$ with 

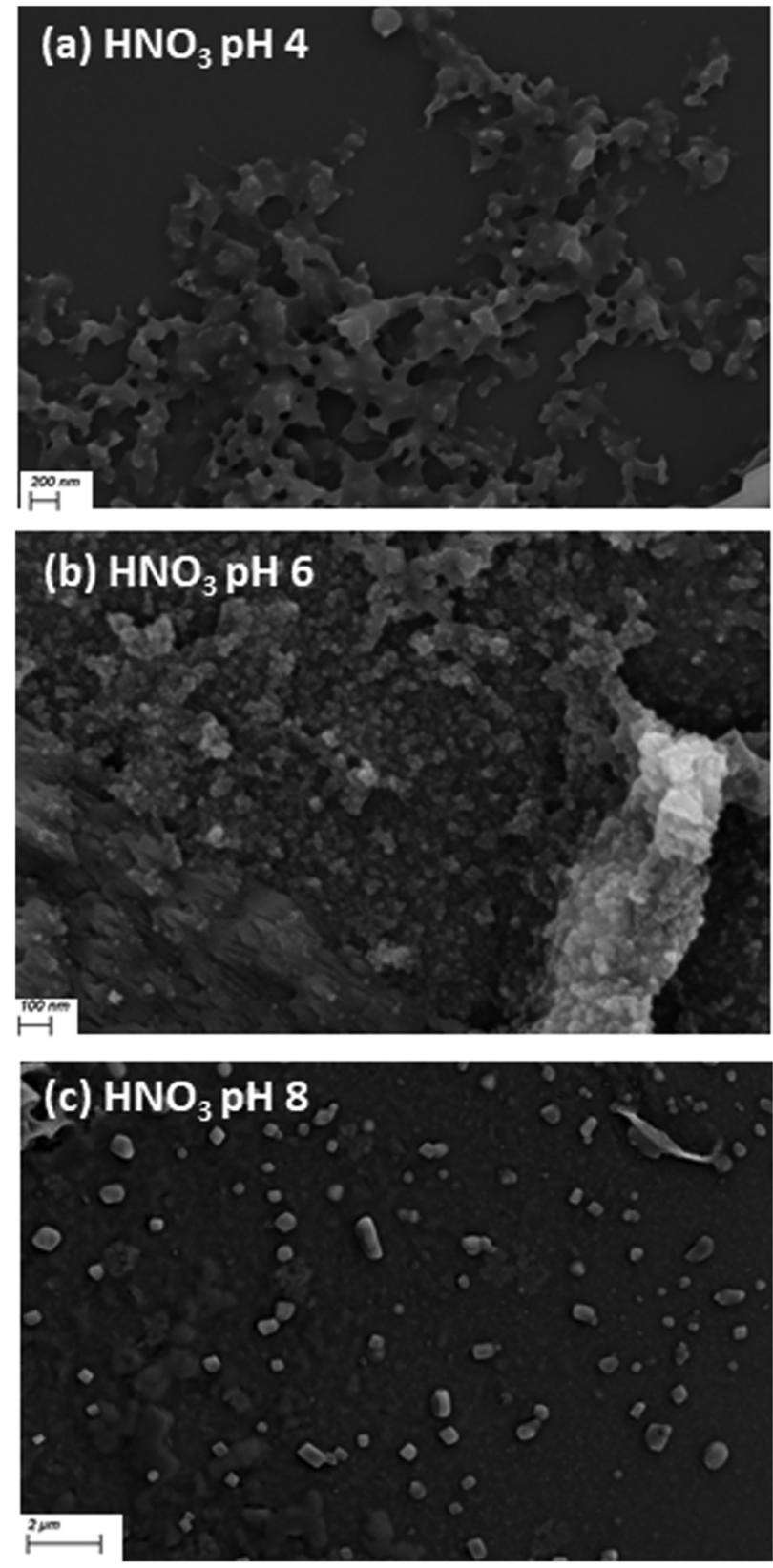

Fig. 10 (a) SEM image of $\mathbf{L} 2$ sample spiked with $\mathrm{HNO}_{3}$ at $\mathrm{pH} 4$ showing a branching morphology of aggregates, (b) SEM image of L2 sample spiked with $\mathrm{HNO}_{3}$ at $\mathrm{pH} 6$ showing a higher density of aggregates (c) SEM image of $\mathbf{L} 2$ sample spiked with $\mathrm{HNO}_{3}$ at $\mathrm{pH} 8$ showing micrometer aggregates.

manganese(II) chloride was analysed by powder X-ray diffraction and the pattern matched the simulated of the ligand as illustrated in Fig. S10 (ESI $\dagger)$. This indicated that only unreacted ligand was recovered, and no other (crystalline) material was formed.

The gels were examined by thermogravimetric analysis and showed a residual non-volatile mass of between $1.0 \%$ and $0.9 \%$ after desolvation, completed by $100{ }^{\circ} \mathrm{C}$ as illustrated in Fig. S61 and $\mathrm{S} 62$ (see $\mathrm{ESI}^{\dagger}$ ). These residual masses were consistent with the combined masses of the gelator mixture from the original synthesis showing the entire solvent content is encapsulated in the continuous gel phase. SEM analysis was carried out on the

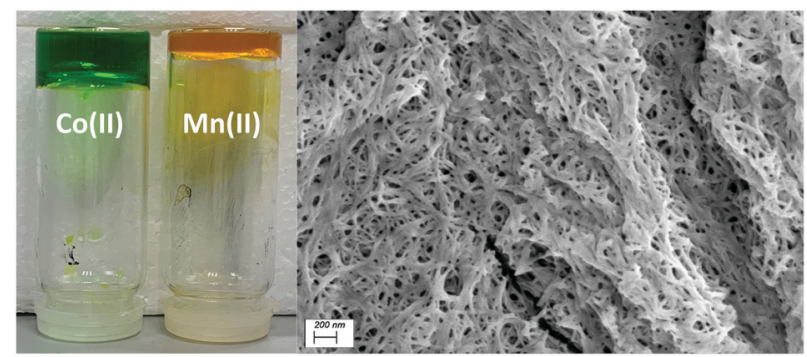

Fig. 11 (left) Co-L1 (gel 2) and Mn-L1 (gel 1) undergoing an inversion test, (right) SEM image indicating the fibrous morphology of the xerogel 2.

materials after desolvation under dynamic vacuum. The resulting xerogels undergo compression into nearly homogeneous films during the drying process. On closer inspection, a rough texture and densely packed fibrous morphology can be observed, conceivably as a remnant of the original gel network as illustrated in Fig. 11 and Fig. S63 (ESI $\dagger$ ).

\section{Chemical properties}

A series of experiments were carried out to measure the response of the gel to external stimuli such as mechanical force, temperature or chemical stimuli. Thermoreversibility properties were exhibited by each of the gels 1 and 2 . At $25{ }^{\circ} \mathrm{C}$, the gels are stable and resistant to inversion indefinitely. On heating, the gels revert to the sol phase, and re-form on standing at room temperature overnight. The gel-sol transition temperature $T_{\mathrm{s}-\mathrm{g}}$ for each gel was measured by holding the set gels in a temperaturecontrolled bath in glass tubes at $45^{\circ}$ inclination and slowly heating until the transition to a homogeneous free flowing liquid was observed. Gel 2 displayed the lower thermal stability, reverting to the liquid phase at $52-54{ }^{\circ} \mathrm{C}$. Gel 1 however retained its form until $74-76{ }^{\circ} \mathrm{C}$, these values are tabulated with measured wt $\%$ in Table S4 (ESI $\dagger$ ).

We carried out investigations into the responsiveness of the gels to a variety of chemical stimuli; in particular $\mathrm{pH}$ responsiveness. The $\mathrm{pH}$ responsiveness of the cobalt gel 2 was examined by adding an $\mathrm{HCl}$ spike $(100 \mu \mathrm{L}, 0.1 \mathrm{M})$ in which the gel broke up and turned pale green, as illustrated in Fig. S64 (ESI $\dagger)$. Upon addition of a $\mathrm{NaOH}$ spike $(100 \mu \mathrm{L}, 0.1 \mathrm{M})$ and brief sonication to disperse the addition evenly, the solution turned yellow. Upon heating to $50{ }^{\circ} \mathrm{C}$ the solution changed colour to green, when sonicated again back to yellow indicating a thermochromic response of the dissolved species. This study was repeated with $\mathrm{H}_{2} \mathrm{O}$, after the first $100 \mu \mathrm{L}$ addition, a yellow layer diffused through the gel indicating the generation of free ligand and $\left[\mathrm{Co}\left(\mathrm{H}_{2} \mathrm{O}\right)_{6}\right]$ species, similarly on the second $100 \mu \mathrm{L}$ addition of $\mathrm{H}_{2} \mathrm{O}$, the same observation was made. Heating and cooling lead to a thermochromic response through the cycled colour change from green to yellow solutions.

These experiments were repeated with gel $\mathbf{1}$ and similarly upon an $\mathrm{HCl}$ spike $(100 \mu \mathrm{L}, 0.1 \mathrm{M})$ the gel broke up into a yellow solution generating the free ligand and $\left[\mathrm{Mn}\left(\mathrm{H}_{2} \mathrm{O}\right)_{6}\right]^{2+}$ species. Subsequent addition of an $\mathrm{NaOH}$ spike $(100 \mu \mathrm{L}, 0.1 \mathrm{M})$ was added and the gel broke up into a yellow solution. This was 
repeated with $\mathrm{H}_{2} \mathrm{O}$ as described above and the gel is stable for 4 hours but slowly breaks up into a yellow solution upon standing overnight. In contrast to gel 2 , heating and cooling incited no thermochromic response. A similar process occurs in solution, but the colour change is not observed due to the weak absorbance from the manganese, which is saturated by the yellow absorbance from the ligand, unlike in the strongly absorbing tetrahedral polychloro-cobaltate ions likely present in solution 2 above.

Following the $\mathrm{pH}$ responsiveness of the gels, a metal sequestration experiment was carried out. Upon addition of a $(100 \mu \mathrm{L}$, $0.1 \mathrm{mmol}$ ) disodium ethylenediaminetetraacetate dihydrate $(\text { EDTA-Na })_{2}$ acetonitrile solution broke up gel $\mathbf{1}$ into a yellow solution. Following this triethylamine $(100 \mu \mathrm{L}, 0.1 \mathrm{mmol})$ acetonitrile solution was added dropwise to the gel forming a green suspension, as illustrated in Fig. S65 (ESI $\dagger$ ). Upon standing for 7 days single yellow needle crystals were formed. The crystals are a second phase of the L1-gel ligand crystals described above.

The fluorescence emission of gels $\mathbf{1}$ and $\mathbf{2}$ were measured as well as their responses to $\mathrm{pH}$ through the addition of a $\mathrm{HCl}$ spike $(100 \mu \mathrm{L}, 0.1 \mathrm{M}), \mathrm{NaOH}$ spike $(100 \mu \mathrm{L}, 0.1 \mathrm{M})$ and $\mathrm{H}_{2} \mathrm{O}(2 \times 100 \mu \mathrm{L})$ spikes to each sample. The normalised fluorescence spectra of gels 1 and 2 indicated a small shift in $\lambda_{\max }$ from $536 \mathrm{~nm}$ to $544 \mathrm{~nm}$ upon addition of $\mathrm{HCl}$ and $\mathrm{NaOH}$. Similarly, the fluorescence was invariant with the first addition of $\mathrm{H}_{2} \mathrm{O}(100 \mu \mathrm{L})$ but a similar shift was observed upon the second addition of $\mathrm{H}_{2} \mathrm{O}$ as illustrated in Fig. 12 and Fig. S66 (ESI $\dagger$ ). The free ligand emission at pH 2 is very similar to the measured spectra for the $200 \mu \mathrm{L}$ of water with a $\lambda_{\max }$ of $545 \mathrm{~nm}$. However, at $\mathrm{pH} 12$ the ligand emission is blue shifted to $536 \mathrm{~nm}$, which is the opposite trend to that observed in the gels.

To investigate the aggregation behaviour of the metallogels, the solution state UV-vis and fluorescence spectra were measured of gels 1 and 2. The normalised spectra were compared to the free ligand spectra measured over the range $1 \times 10^{-4} \mathrm{M}$ to $1 \times 10^{-6} \mathrm{M}$ (ESI, $\dagger$ Fig. S67 and S68) and indicated a small shift in $\lambda_{\mathrm{em}}$ from the free ligand in $\mathrm{H}_{2} \mathrm{O}(520 \mathrm{~nm})$ to the gel $(527 \mathrm{~nm})$ to the free ligand in $\mathrm{CH}_{3} \mathrm{CN}$ (533 nm). No change was observed in the band shape compared to the free ligand. Additionally, Fourier

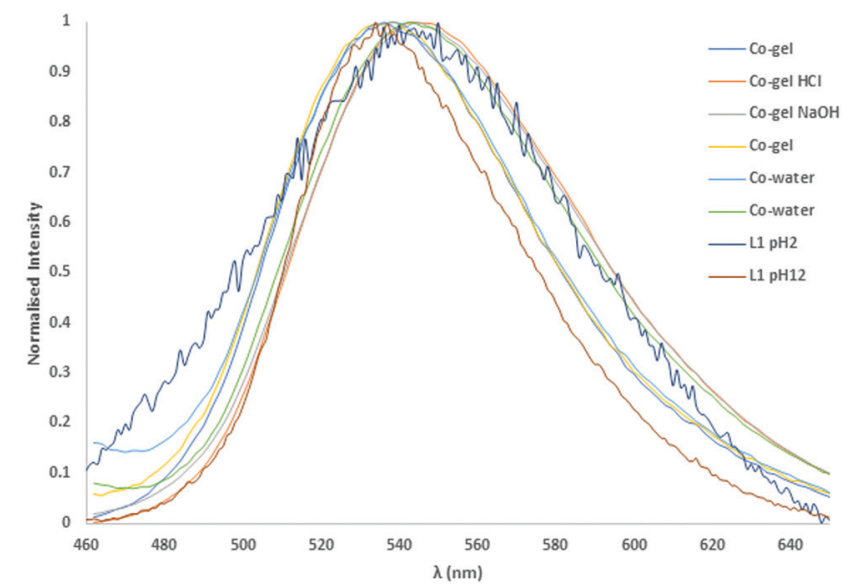

Fig. 12 Normalised solid-state fluorescence of the L1 metallogels, compared with the parent ligand, and the response to $\mathrm{pH}$ changes.
Transform infrared (FTIR) spectroscopy was also used to probe the dried xerogels of $\mathbf{1}$ and $\mathbf{2}$ and compared to the free ligand L1. In both cases there was a small shift of approx. $8 \mathrm{~cm}^{-1}$ in the carbonyl $\mathrm{C}=\mathrm{O}$ stretching band from $1694 \mathrm{~cm}^{-1}$ to $1686 \mathrm{~cm}^{-1}$. In gel 1, there was also the formation of a weak band at $1739 \mathrm{~cm}^{-1}$ observed as illustrated in Fig. S69 and S70 (ESI $\dagger$ ), though no other notable changes to the ligand absorbances were observed.

To measure the effect of the metal ion on the aggregation of L1, the UV-vis and fluorescence emission spectra was measured of sequential 0.2 eq. additions of cobalt(II) or manganese(II) to L1 until 1 eq. was reached (as illustrated in Fig. S71 and S72, ESI $\dagger$ ). On comparison of this normalised spectra to the free ligand $\mathbf{L 1}$ as well as spectra of gels $\mathbf{1}$ and $\mathbf{2}$ no significant changes were observed (Fig. S69 and S70, ESI $\dagger$ ). FTIR spectra
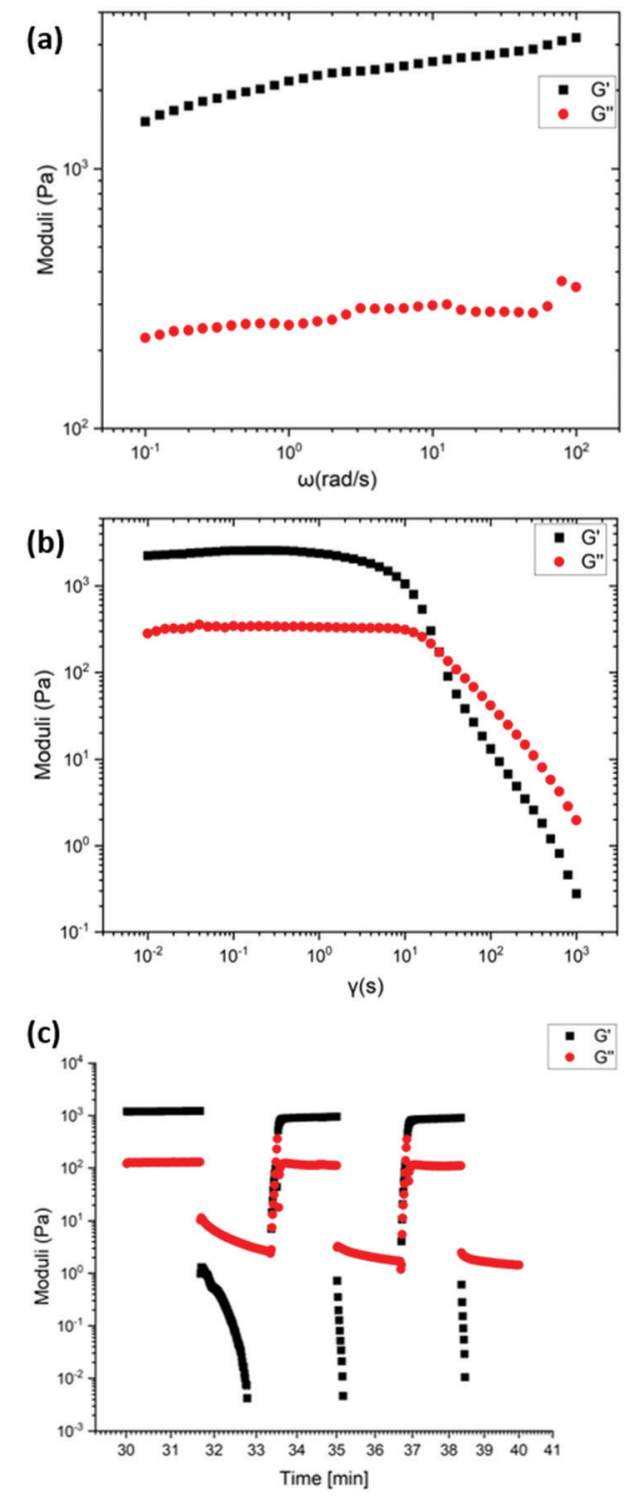

Fig. 13 Rheological studies for gel 2 prepared at $1.7 \mathrm{wt} \%$ in acetonitrile, showing (a) frequency sweep over consecutive cycles $(\gamma=0.1 \%$ ), (b) amplitude sweep $\left(\omega=1 \mathrm{rad} \mathrm{s}^{-1}\right)$ and (c) recovery test at alternating $0.1 \%$ and $500 \%$ strain amplitudes. 
were also measured of dried samples of the M:L mixtures, as illustrated in the overlaid spectra (Fig. S73 and S74, ESI $\dagger$ ) no significant changes were observed and the spectra remained largely similar to that of the free ligand.

\section{Rheological studies}

Rheological studies (strain and frequency sweeps) and recovery tests were performed on the most robust gels 1 and 2 (Mn-L1 and Co-L1) to quantitatively study the mechanical properties of the metallogels. Each material studied was prepared using identical procedures to maintain equivalent ligand fractions for each sample. The gels were illustrated to possess viscoelastic properties often associated with supramolecular gel-phase materials.

The frequency sweep for gel 2 showed the $G^{\prime}$ value (1520 Pa) which is $1300 \mathrm{~Pa}$ higher than the $G^{\prime \prime}$ value $(220 \mathrm{~Pa})$, which is characteristic of gel behaviour. Similarly, the frequency sweep for gel 1 showed the $G^{\prime}$ value (1400 Pa) which is $1200 \mathrm{~Pa}$ higher than the $G^{\prime \prime}$ value (200 $\mathrm{Pa}$ ), which is also characteristic of gel behaviour. Following this, to test the strength of the gel, strain tests were carried out. At low strain amplitudes, the storage modulus, $G^{\prime}$ and the loss modulus $G^{\prime \prime}$, of the gel remains constant until the onset of liquid-like behaviour. For gel 2, the intersection of the $G^{\prime}$ and $G^{\prime \prime}$ curves occurred at 172 Pa with $25 \%$ strain amplitude. For gel $\mathbf{1}$, the intersection of the $G^{\prime}$ and $G^{\prime \prime}$ curves occurred at $130 \mathrm{~Pa}$ with $40 \%$ strain amplitude. The values of $G^{\prime}$ and $G^{\prime \prime}$ for gels 1 and 2 did not vary significantly with frequency under a frequency sweep in the range 0.1-100 rad s $\mathrm{s}^{-1}$, Fig. 13 and Fig. S75 (ESI $\dagger$ ).

The recovery properties of the gels were tested in an oscillatory recovery test, by imposing alternating strain amplitudes of $500 \%$ and $0.1 \%$ at constant $1 \mathrm{~Hz}$ oscillation frequency. Each of the gels displayed transitions from liquid-like $\left(G^{\prime \prime}>G^{\prime}\right)$ to solidlike $\left(G^{\prime}>G^{\prime \prime}\right)$ behaviour within $c a .100 \mathrm{~s}$. While the gels do not fully recover, the gels recover $80 \%$ of the original low-strain values of the storage and the loss moduli.

\section{Conclusions}

We have prepared and structurally characterised two new 4-( $N$-morpholino)-1,8-naphthalimide ligands and reported on their solution and gelation chemistry in response to $\mathrm{pH}$ and the presence of d-block metal ions. The solid-state characterisation of $\mathbf{L} \mathbf{1}$ and $\mathbf{L} 2$ illustrated both the influence of solvent and substituent on the structure directionality. In the solution state L1 was observed to undergo a $\mathrm{pH}$ and anion-dependent aggregation process which contributes to a sharp increase in fluorescence emission, and a hysteresis effect. This indicates that the change in the absorption and fluorescence is not only associated with a simple protonation and deprotonation process but also the additional effect of supramolecular organization, which led to the formation of microparticles. The tunability of this system was examined through substituting the $N$-position with benzyl amine and in the solution state $\mathbf{L} 2$ also undergoes an aggregation process. The formation of aggregates over the
$\mathrm{pH}$ range was investigated further by using DLS and SEM measurements which demonstrated the presence of micrometre-scale aggregates in solution. Following this, the supramolecular assembly characteristics of these systems were investigated by examining the interaction of $\mathbf{L 1}$ and $\mathbf{L} 2$ with other Lewis acids. By using first row divalent transition metals as our test basis, two metallogels were generated from $\mathbf{L 1}$ and the gels response to various physical and chemical stimuli, including $\mathrm{pH}$, metal sequestration and thermal responsiveness were examined. The ligands presented here illustrate a structure-function relationship in the ligand design which can be used as a handle for developing the unique variation in photophysical properties of this system, which provides a future role in the design of $\mathrm{pH}$ responsive supramolecular materials.

\section{Conflicts of interest}

There are no conflicts to declare.

\section{Acknowledgements}

The authors gratefully acknowledge Science Foundation Ireland (PI award 13/IA/1865 to T. G.), CDA award 17/CDA/4704 to M. E. M., the SFI Centre AMBER (for Research Centres Phase 2 12/RC/ 2278_P2) and the SFI Centre SSPC (for Research Centres Phase 2 12/RC/2275_P2) to T. G., Trinity College Dublin and the School of Chemical and Physical Sciences, Keele University.

\section{Notes and references}

1 (a) B. O. Okesola and D. K. Smith, Applying low-molecular weight supramolecular gelators in an environmental setting - self-assembled gels as smart materials for pollutant removal, Chem. Soc. Rev., 2016, 45, 4226-4251; (b) J. Li, J. Wang, H. Li, N. Song, D. Wang and B. Z. Tang, Supramolecular materials based on AIE luminogens (AIEgens): construction and applications, Chem. Soc. Rev., 2020, 49, 1144-1172; (c) G. Tseberlidis, D. Intrieri and A. Caselli, Catalytic Applications of Pyridine-Containing Macrocyclic Complexes, Eur. J. Inorg. Chem., 2017, 3589-3603; (d) D. Écija, J. I. Urgel, A. P. Seitsonen, W. Auwärter and J. V. Barth, Lanthanide-Directed Assembly of Interfacial Coordination Architectures - From Complex Networks to Functional Nanosystems, Acc. Chem. Res., 2018, 51, 365-375; (e) I. V. Kolesnichenko and E. V. Anslyn, Practical applications of supramolecular chemistry, Chem. Soc. Rev., 2017, 46, 2385-2390; $(f)$ T. Gorai, W. Schmitt and T. Gunnlaugsson, Highlights of the development and application of luminescent lanthanide based coordination polymers, MOFs and functional nanomaterials, Dalton Trans., 2021, 50, 770-784; (g) A. J. Savyasachi, O. Kotova, S. Shanmugaraju, S. J. Bradberry, G. M. Ó’Máille and T. Gunnlaugsson, Supramolecular Chemistry: A Toolkit for Soft Functional Materials and Organic Particles, Chem, 2017, 3, 764-811. 
2 (a) C. D. Jones and J. W. Steed, Gels with sense: supramolecular materials that respond to heat, light and sound, Chem. Soc. Rev., 2016, 45, 6546-6596; (b) T. Feldner, M. Häring, S. Saha, J. Esquena, R. Banerjee and D. D. Díaz, Supramolecular Metallogel That Imparts Self-Healing Properties to Other Gel Networks, Chem. Mater., 2016, 28, 3210-3217; (c) M. Externbrink, S. Riebe, C. Schmuck and J. Voskuhl, A dual pH-responsive supramolecular gelator with aggregation-induced emission properties, Soft Matter, 2018, 14, 6166-6170.

3 (a) Z. Li, J. R. Askim and K. S. Suslick, The Optoelectronic Nose: Colorimetric and Fluorometric Sensor Arrays, Chem. Rev., 2019, 119, 231-292; (b) P. A. Gale and C. Caltagirone, Fluorescent and colorimetric sensors for anionic species, Coord. Chem. Rev., 2018, 354, 2-27; (c) L. M. Mesquita, V. André, C. V. Esteves, T. Palmeira, M. N. Berberan-Santos, P. Mateus and R. Delgado, Dinuclear Zinc(II) Macrocyclic Complex as Receptor for Selective Fluorescence Sensing of Pyrophosphate, Inorg. Chem., 2016, 55, 2212-2219; (d) J. J. Lee, Y. S. Kim, E. Nam, S. Y. Lee, M. H. Lim and C. Kim, A PET-based fluorometric chemosensor for the determination of mercury(ii) and $\mathrm{pH}$, and hydrolysis reaction-based colorimetric detection of hydrogen sulfide, Dalton Trans., 2016, 45, 5700-5712; (e) D. Wu, A. C. Sedgwick, T. Gunnlaugsson, E. U. Akkaya, J. Yoon and T. D. James, Fluorescent chemosensors: the past, present and future, Chem. Soc. Rev., 2017, 46, 7105-7123.

4 (a) R. Parkesh, T. Clive Lee and T. Gunnlaugsson, Highly selective 4-amino-1,8-naphthalimide based fluorescent photoinduced electron transfer (PET) chemosensors for $\mathrm{Zn}$ (ii) under physiological pH conditions, Org. Biomol. Chem., 2007, 5, 310-317; (b) A. P. de Silva, H. Q. N. Gunaratne, T. Gunnlaugsson, A. J. M. Huxley, C. P. McCoy, J. T. Rademacher and T. E. Rice, Signaling Recognition Events with Fluorescent Sensors and Switches, Chem. Rev., 1997, 97, 1515-1566.

5 (a) E. E. Langdon-Jones, D. Lloyd, A. J. Hayes, S. D. Wainwright, H. J. Mottram, S. J. Coles, P. N. Horton and S. J. A. Pope, Alkynyl-naphthalimide Fluorophores: Gold Coordination Chemistry and Cellular Imaging Applications, Inorg. Chem., 2015, 54, 6606-6615; (b) D. L. Reger, A. P. Leitner and M. D. Smith, Supramolecular Metal-Organic Frameworks of S- and f-Block Metals: Impact of 1,8-Naphthalimide Functional Group, Cryst. Growth Des., 2016, 16, 527-536; (c) A. B. Carter, N. Zhang, I. A. Kühne, T. D. Keene, A. K. Powell and J. A. Kitchen, Layered Ln(III) Complexes from a SulfonateBased 1,8-Naphthalimide: Structures, Magnetism and Photophysics, ChemistrySelect, 2019, 4, 1850-1856; (d) D. L. Reger, J. J. Horger and M. D. Smith, Copper(ii) carboxylate tetramers formed from an enantiopure ligand containing a $\pi$-stacking supramolecular synthon: single-crystal to single-crystal enantioselective ligand exchange, Chem. Commun., 2011, 47, 2805-2807.

6 (a) M. Martínez-Calvo, S. A. Bright, E. B. Veale, A. F. Henwood, D. C. Williams and T. Gunnlaugsson, 4-Amino-1,8-naphthalimide based fluorescent photoinduced electron transfer (PET) pH sensors as liposomal cellular imaging agents: The effect of substituent patterns on PET directional quenching, Front. Chem. Sci. Eng., 2020, 14, 61-75; (b) Y. Ni, Z. Sun,
Y. Wang, H. F. Nour, A. C. H. Sue, N. S. Finney, K. K. Baldridge and M. A. Olson, Versatile hydrochromic fluorescent materials based on a 1,8-naphthalimide integrated fluorophore-receptor system, J. Mater. Chem., 2019, 7, 7399-7410.

7 (a) R. M. Duke and T. Gunnlaugsson, 3-Urea-1,8-naphthalimides are good chemosensors: a highly selective dual colorimetric and fluorescent ICT based anion sensor for fluoride, Tetrahedron Lett., 2011, 52, 1503-1505; (b) R. M. Duke, E. B. Veale, F. M. Pfeffer, P. E. Kruger and T. Gunnlaugsson, Colorimetric and fluorescent anion sensors: an overview of recent developments in the use of 1,8-naphthalimide-based chemosensors, Chem. Soc. Rev., 2010, 39, 3936-3953.

8 (a) Y. Tang, Y. Ma, J. Yin and W. Lin, Strategies for designing organic fluorescent probes for biological imaging of reactive carbonyl species, Chem. Soc. Rev., 2019, 48, 4036-4048; (b) H.-J. Lee, C.-W. Cho, H. Seo, S. Singha, Y. W. Jun, K.-H. Lee, Y. Jung, K.-T. Kim, S. Park, S. C. Bae and K. H. Ahn, A two-photon fluorescent probe for lysosomal zinc ions, Chem. Commun., 2016, 52, 124-127; (c) S.-H. Park, N. Kwon, J.-H. Lee, J. Yoon and I. Shin, Synthetic ratiometric fluorescent probes for detection of ions, Chem. Soc. Rev., 2020, 49, 143-179; (d) C. L. Fleming, T. D. Ashton, C. Nowell, M. Devlin, A. Natoli, J. Schreuders and F. M. Pfeffer, A fluorescent histone deacetylase (HDAC) inhibitor for cellular imaging, Chem. Commun., 2015, 51, 7827-7830.

9 (a) J. Mayr, C. Saldías and D. Díaz Díaz, Release of small bioactive molecules from physical gels, Chem. Soc. Rev., 2018, 47, 1484-1515; (b) E. Saha and J. Mitra, MultistimuliResponsive Self-Healable and Moldable Nickel(II)-Based Gels for Reversible Gas Adsorption and Palladium Sequestration via Gel-to-Gel Transformation, ACS Appl. Mater. Interfaces, 2019, 11, 10718-10728; (c) J. Li, L. Geng, G. Wang, H. Chu and H. Wei, Self-Healable Gels for Use in Wearable Devices, Chem. Mater., 2017, 29, 8932-8952; (d) S. Ganta and D. K. Chand, Multi-Stimuli-Responsive Metallogel Molded from a Pd2L4-Type Coordination Cage: Selective Removal of Anionic Dyes, Inorg. Chem., 2018, 57, 3634-3645; (e) E. R. Draper and D. J. Adams, Low-Molecular-Weight Gels: The State of the Art, Chem, 2017, 3, 390-410.

10 (a) S. Panja, S. Bhattacharya and K. Ghosh, Pyridine coupled mono and bisbenzimidazoles as supramolecular gelators: selective metal ion sensing and ionic conductivity, Mater. Chem. Front., 2018, 2, 385-395; (b) A. Pal, S. Chand and M. C. Das, A Water-Stable Twofold Interpenetrating Microporous MOF for Selective $\mathrm{CO} 2$ Adsorption and Separation, Inorg. Chem., 2017, 56, 13991-13997; (c) S. Chand, A. Pal, S. C. Pal and M. C. Das, A Trifunctional Luminescent 3D Microporous MOF with Potential for CO2 Separation, Selective Sensing of a Metal Ion, and Recognition of a Small Organic Molecule, Eur. J. Inorg. Chem., 2018, 2785-2792; (d) D. Dietrich, C. Licht, A. Nuhnen, S.-P. Höfert, L. De Laporte and C. Janiak, Metal-Organic Gels Based on a Bisamide Tetracarboxyl Ligand for Carbon Dioxide, Sulfur Dioxide, and Selective Dye Uptake, ACS Appl. Mater. Interfaces, 2019, 11, 19654-19667; (e) C. K. Karan, M. C. Sau and M. Bhattacharjee, A copper(ii) metal-organic hydrogel as a 
multifunctional precatalyst for CuAAC reactions and chemical fixation of $\mathrm{CO} 2$ under solvent free conditions, Chem. Commun., 2017, 53, 1526-1529.

11 N. Kelly, K. Gloe, T. Doert, F. Hennersdorf, A. Heine, J. März, U. Schwarzenbolz, J. J. Weigand and K. Gloe, Self-assembly of [2+2] $\mathrm{Co}$ (II) metallomacrocycles and $\mathrm{Ni}(\mathrm{II})$ metallogels with novel bis(pyridylimine) ligands, J. Organomet. Chem., 2016, 821, 182-191.

12 J.-L. Zhong, X.-J. Jia, H.-J. Liu, X.-Z. Luo, S.-G. Hong, N. Zhang and J.-B. Huang, Self-assembled metallogels formed from $\mathrm{N}, \mathrm{N}^{\prime}, \mathrm{N}^{\prime \prime}$-tris(4-pyridyl)trimesic amide in aqueous solution induced by Fe(iii)/Fe(ii) ions, Soft Matter, 2016, 12, 191-199.

13 (a) C. K. Karan and M. Bhattacharjee, Self-Healing and Moldable Metallogels as the Recyclable Materials for Selective Dye Adsorption and Separation, ACS Appl. Mater. Interfaces, 2016, 8, 5526-5535; (b) S. Bhattacharjee, B. Maiti and S. Bhattacharya, First report of charge-transfer induced heat-set hydrogel. Structural insights and remarkable properties, Nanoscale, 2016, 8, 11224-11233.

14 (a) A. D. Lynes, C. S. Hawes, E. N. Ward, B. Haffner, M. E. Möbius, K. Byrne, W. Schmitt, R. Pal and T. Gunnlaugsson, Benzene1,3,5-tricarboxamide n-alkyl ester and carboxylic acid derivatives: tuneable structural, morphological and thermal properties, CrystEngComm, 2017, 19, 1427-1438; (b) O. Kotova, R. Daly, C. M. G. dos Santos, M. Boese, P. E. Kruger, J. J. Boland and T. Gunnlaugsson, Europium-Directed SelfAssembly of a Luminescent Supramolecular Gel from a Tripodal Terpyridine-Based Ligand, Angew. Chem., Int. Ed., 2012, 51, 7208-7212; (c) R. Daly, O. Kotova, M. Boese, T. Gunnlaugsson and J. J. Boland, Chemical Nano-Gardens: Growth of Salt Nanowires from Supramolecular SelfAssembly Gels, ACS Nano, 2013, 7, 4838-4845.

15 (a) O. Kotova, S. J. Bradberry, A. J. Savyasachi and T. Gunnlaugsson, Recent advances in the development of luminescent lanthanide-based supramolecular polymers and soft materials, Dalton Trans., 2018, 47, 16377-16387; (b) O. Kotova, R. Daly, C. M. G. dos Santos, P. E. Kruger, J. J. Boland and T. Gunnlaugsson, Cross-Linking the Fibers of Supramolecular Gels Formed from a Tripodal Terpyridine Derived Ligand with d-Block Metal Ions, Inorg. Chem., 2015, 54, 7735-7741; (c) M. Klein-Hitpaß, A. D. Lynes,
C. S. Hawes, K. Byrne, W. Schmitt and T. Gunnlaugsson, A Schiff-base cross-linked supramolecular polymer containing diiminophenol compartments and its interaction with copper(II) ions, Supramol. Chem., 2018, 30, 93-102.

16 (a) S. J. Bradberry, G. Dee, O. Kotova, C. P. McCoy and T. Gunnlaugsson, Luminescent lanthanide (Eu(iii)) crosslinked supramolecular metallo co-polymeric hydrogels: the effect of ligand symmetry, Chem. Commun., 2019, 55, 1754-1757; (b) E. P. McCarney, J. P. Byrne, B. Twamley, M. Martínez-Calvo, G. Ryan, M. E. Möbius and T. Gunnlaugsson, Self-assembly formation of a healable lanthanide luminescent supramolecular metallogel from 2,6-bis(1,2,3-triazol-4-yl)pyridine (btp) ligands, Chem. Commun., 2015, 51, 14123-14126.

17 I. N. Hegarty, H. L. Dalton, A. D. Lynes, B. Haffner, M. E. Möbius, C. S. Hawes and T. Gunnlaugsson, Balancing connectivity with function in silver(i) networks of pyridyltriazole (tzpa) ligands results in the formation of a metallogel, Dalton Trans., 2020, 49, 7364-7372.

18 J. I. Lovitt, C. S. Hawes, A. D. Lynes, B. Haffner, M. E. Möbius and T. Gunnlaugsson, Coordination chemistry of N-picolyl1,8-naphthalimides: colourful low molecular weight metallogelators and unique chelation behaviours, Inorg. Chem. Front., 2017, 4, 296-308.

19 L. J. Beeching, C. S. Hawes, D. R. Turner and S. R. Batten, The influence of anion, ligand geometry and stoichiometry on the structure and dimensionality of a series of AgIbis(cyanobenzyl)piperazine coordination polymers, CrystEngComm, 2014, 16, 6459-6468.

20 J. Bernstein, R. E. Davis, L. Shimoni and N.-L. Chang, Patterns in Hydrogen Bonding: Functionality and Graph Set Analysis in Crystals, Angew. Chem., Int. Ed. Engl., 1995, 34, 1555-1573.

21 E. Calatrava-Pérez, S. Acherman, L. Stricker, G. McManus, J. Delente, A. D. Lynes, A. F. Henwood, J. I. Lovitt, C. S. Hawes, K. Byrne, W. Schmitt, O. Kotova, T. Gunnlaugsson and E. M. Scanlan, Fluorescent supramolecular hierarchical selfassemblies from glycosylated 4-amino- and 4-bromo-1,8naphthalimides, Org. Biomol. Chem., 2020, 18, 3475-3480.

22 N. Mataga, Y. Kaifu and M. Koizumi, Solvent Effects upon Fluorescence Spectra and the Dipolemoments of Excited Molecules, Bull. Chem. Soc. Jpn., 1956, 29, 465-470. 